\title{
PENERAPAN METODE INQUIRY TERHADAP HASIL BELAJAR SISWA PADA MATA PELAJARAN IPS TERPADU DALAM MATERI KERAGAMAN FLORA DAN FAUNA DI INDONESIA DI KELAS VII SMP NEGERI 1 TEBAS
}

\author{
Agus Suwarno \\ Prodi Geografi IKIP PGRI Pontianak \\ Kalimantan Barat, Indonesia
}

\section{Info Artikel}

\section{Sejarah Artikel:}

Diterima Juli 2016

Disetujui Oktober 2016

Dipublikasikan Desember 2016

\section{Keywords:}

Methods of Inquiry,

Learning Outcomes

\begin{abstract}
The problem in this research is "Implementation Methods of Inquiry Against Student Results At Subjects IPS Integrated In Creative Diversity Flora And Fauna In Indonesia In Class VII Junior High School 1 Tebas", with sub-problems of research: (1) student learning control class who did not apply his method of inquiry in social studies Integrated in the material diversity of flora and fauna in Indonesia in class VII SMP Negeri 1 Tebas. (2) The results of the experimental class students learn to apply methods of inquiry in social studies Integrated in the material diversity of flora and fauna in Indonesia in class VII SMP Negeri 1 Tebas. (3) The difference in student learning outcomes with the experimental class control class that implements the method of inquiry in social studies Integrated in the material diversity of flora and fauna in Indonesia in class VII SMP Negeri 1 Tebas. The variables in this study consisted of the dependent variable and independent variables, the independent variable of this research is the result of learning and the independent variables are methods of inquiry. This study used an experimental method, the research is a form of quasi-experimental research or experiment with the study design quasy two-group post-test only design. The population in this study the entire seventh grade students totaling 196 people. The sampling technique using cluster sampling. Data collection techniques used in this study is the direct observation techniques, measurement techniques, and documentary techniques. And tools used are observation sheets (IPKG 2), achievement test, and documentation. Based on the analysis and discussion of data obtained: (1) the average student learning outcomes in control class is 69.62 which is quite enough. (2) The results of the calculation, the average student learning outcomes in the experimental class at 73.23 which is quite good. (3) based on calculations using the test was obtained $t_{\text {count }} \geq t_{\text {table }}, 2.27 \geq 2.00$ then there is a difference in student learning outcomes with the experimental class control class that implements methods of inquiry.
\end{abstract}


belajar siswa pada kelas eksperimen sebesar 73.23 yang tergolong baik. (3) berdasarkan hasil perhitungan menggunakan uji $\mathrm{t}$ di peroleh nilai $\mathrm{t}_{\text {hitung }} \geq \mathrm{t}_{\text {tabel }}, 2.27 \geq 2.00$ maka terdapat perbedaan hasil belajar siswa kelas kontrol dengan kelas eksperimen yang menerapkan metode inquiry.

(C) 2016 Universitas Muria Kudus

Alamat korespondensi:

Program Studi Pendidikan Guru Sekolah Dasar

p-ISSN 2087-9385

Fakultas Keguruan dan Ilmu Pendidikan Universitas Muria Kudus

e-ISSN 2528-696X

Kampus UMK Gondangmanis, Bae Kudus Gd. L. It I PO. BOX 53 Kudus

Tlp (0291) 438229 ex.147 Fax. (0291) 437198

E-mail: agoessaja @gmail.com 


\section{PENDAHULUAN}

Pendidikan dipercaya mampu menanamkan kapasitas baru bagi semua orang untuk mempelajari pengetahuan dan keterampilan. Salah satu hal mendasar dalam dunia pendidikan adalah bagaimana usaha untuk meningkatkan proses belajar mengajar sehingga memperoleh hasil yang efektif dan efisien. Proses belajar mengajar yang efektif dan efisien bisa kita dapat di sekolah, karena sekolah merupakan lembaga pendidikan yang memiliki peranan penting dalam memajukan pendidikan yang lebih baik. Lembaga pendidikan yang baik dapat membentuk sumber daya manusia yang mampu bersaing di era globalisasi. Pembentukan sumber daya manusia melalui lembaga pendidikan dapat dicapai melalui proses pembelajaran di sekolah.

Pembelajaran merupakan suatu proses atau kegiatan yang di dalamnya terjadi interaksi antara guru dan siswa atau antara siswa yang memiliki suatu tujuan tertentu, baik interaksi secara langsung dan tidak langsung. Secara langsung seperti kegiatan tatap muka, dan secara tidak langsung yaitu dengan menggunakan berbagai media pembelajaran. Peningkatan kualitas pembelajaran merupakan suatu kegiatan penting yang harus diperhatikan, suatu proses belajar mengajar bertujuan untuk meningkatkan mutu pendidikan. Peningkatan kualitas pembelajaran merupakan tugas bagi masing-masing sekolah dan yang paling utama adalah bagi guru sebagai tenaga pengajar. Pendidik dituntut kreatif dan inovatif dalam proses pembelajaran agar siswa lebih mudah memahami materi yang disampaikan dan antusias dalam mengikuti proses belajar mengajar, sehingga pembelajaran yang dilaksanakan berkualitas dan prestasi yang dicapai siswa memuaskan. Upaya untuk meningkatkan keberhasilan belajar melalui pembelajaran aktif dimana siswa melakukan sebagian besar pekerjaan yang harus dilakukan. Siswa menggunakan pikirannya untuk melakukan pekerjaannya, mengeluarkan gagasan, memecahkan masalah dan dapat menerapkan apa yang mereka pelajari. Penggunaan metode pembelajaran yang dapat dijadikan sebagai alternatif guru dalam proses pembelajaran, memiliki tujuan agar siswa mampu belajar dengan baik. Salah satu upaya meningkatkan hasil belajar, yakni pemilihan atau penggunaan metode pembelajaran yang dapat meningkatkan keaktifan siswa dan mencapai tujuan belajar siswa, perlu kiranya diterapkan metode pembelajaran yang dinilai mampu mengatasi permasalahan belajar siswa, salah satunya adalah melalui pemilihan metode inquiry.

Hasil belajar merupakan indikator keberhasilan yang telah dicapai oleh siswa setelah mengikuti proses belajar mengajar. Hasil belajar siswa dipengaruhi oleh potensi siswa sendiri, sekolah, lingkungan masyarakat, dan dipengaruhi oleh kemampuan guru dalam melaksanakan kegiatan atau proses pembelajaran. Hasil belajar yang dicapai siswa meliputi beberapa ranah, yaitu ranah kognitif, ranah afektif, dan ranah psikomotorik. Prinsip yang mendasari penilaian hasil belajar yaitu bagi siswa dan guru untuk dapat meningkatkan kualitas pembelajaran. Pencapaian hasil belajar yang tidak maksimal dapat disebabkan oleh beberapa faktor, yaitu faktor yang berasal dari siswa dan faktor yang berasal dari guru.

Faktor yang berasal dari siswa meliputi kurangnya motivasi siswa terhadap mata pelajaran IPS Terpadu dalam materi keragaman flora dan fauna di Indonesia, tingkat penerimaan, dan pengingatan bahan ajar. Faktor yang berasal dari guru meliputi kurangnya kemampuan membangun hubungan dengan siswa, kemampuan menggerakan minat pelajaran, kemampuan memberikan penjelasan, kemampuan menyebutkan pokok-pokok masalah yang di ajarkan, kemampuan mengarahkan perhatian pada pelajaran yang sedang berlangsung, dan memberikan tanggapan terhadap reaksi siswa. Permasalahan tersebut yang ditemukan di Sekolah Menengah Pertama Negeri I Tebas yang mengakibatkan penguasaan materi keragaman flora dan fauna di Indonesia yang diterima tidak maksimal khususnya pada siswa kelas VII sehingga mengakibatkan hasil belajar siswa rendah.

Berdasarkan uraian di atas, penulis ingin mengetahui lebih lanjut mengenai "Penerapan Metode Inquiry Terhadap Hasil Belajar Siswa Pada Mata Pelajaran IPS Terpadu Dalam Materi Keragaman Flora Dan Fauna Di Indonesia Di Kelas VII Sekolah Menengah Pertama Negeri 1 Tebas".

\section{METODE}

Metode yang dianggap cocok dan tepat digunakan dalam penelitian ini adalah metode eksperimen semu. Amirul Hadi dan Haryono (2005: 53), menyatakan bahwa "penelitian 
eksperimen dilakukan dengan memberikan perlakuan-perlakuan tertentu terhadap kelompok eksperimen dengan kondisi-kondisi yang dapat dikontrol" selanjutnya Sugiyono (2012: 114), mengatakan bahwa: "Eksperimen semu adalah jenis eksperimen yang mempunyai kelompok kontrol, tetapi tidak dapat berfungsi sepenuhnya untuk mengontrol variabel-variabel luar yang mempengaruhi pelaksanaan eksperimen". Rancangan penelitian yang digunakan dalam penelitian ini adalah Two Group Post Tes Only.

Populasi dalam penelitian ini adalah kelas VII di Sekolah Menengah Pertama Negeri 1 Tebas yang berjumlah 196 orang. Dengan karakteristik populasi merupakan siswa kelas VII di Sekolah Menengah Pertama Negeri 1 Tebas tahun ajaran 2014/ 2015. Sedangkan kelas control dan kelas eksperimen adalah kelas kelas VII C yang berjumlah 32 orang siswasiswi sebagai kelas kontrol dan kelas VII F yang berjumlah 34 orang siswa-siswi yang di tentukan dengan cluster sampling.

\section{HASIL DAN PEMBAHASAN}

Dalam penelitian yang dilakukan pada SMP Negeri 1 Tebas, pada kelas kontrol kegiatan pembelajaran tidak menerapkan metode inquiry dimana guru menggunakan metode ceramah yang proses pembelajarannya cenderung berlangsung monoton sehingga siswa kurang aktif malah cenderung pasif. Siswa cenderung menunggu dan mendengarkan penjelasan dari guru. Berbeda dengan kelas eksperimen yang menerapkan metode inquiry, kegiatan pembelajaran berlangsung dengan baik, hal ini dikarenakan metode inquiry ini menempatkan siswa pada posisi sangat dominan dalam proses pembelajaran dan terjadinya kerjasama dalam kelompok sehingga semua siswa berusaha untuk memahami dan mengetahui setiap jawaban dari pertanyaan yang diajukan oleh guru dan bertanggung jawab atas anggota kelompoknya masing-masing, sehingga siswa terlibat secara total dan berperan aktif saat proses pembelajaran berlangsung. Rangkuman hasil belajar antara 2 kelas control dan kelas eksperimen dapat dilihat pada table berikut:

Tabel 1. Rangkuman Hasil belajar Kelas

Kontrol Dan Kelas Eksperimen

\begin{tabular}{lll}
\hline $\begin{array}{l}\text { Hasil Belajar } \\
\text { Siswa }\end{array}$ & $\begin{array}{l}\text { Rata-rata } \\
\text { Nilai }\end{array}$ & $\begin{array}{l}\text { Standar } \\
\text { Deviasi }\end{array}$ \\
\hline Kelas Kontrol & 69,62 & 7,864 \\
\hline
\end{tabular}

\begin{tabular}{lll}
\hline Kelas Eksperimen & 73,23 & 9,358
\end{tabular}

Berdasarkan Tabel 1 di atas dapat diinterprestasikan bahwa hasil belajar siswa yang tidak menerapkan metode inquiry tergolong cukup yaitu 69,62 sedangkan hasil belajar siswa yang menerapkan metode inquiry tergolong baik dengan rata-rata nilai 73,23. adapun rentang atau kriteria yang digunakan sebagai berikut : 0 - 40 Tergolong gagal, $50-$ 59 Tergolong kurang, $60-69$, Tergolong cukup, 70 - 79 Tergolong baik, $80-100$ Tergolong istimewa (Subana dkk, 2000:63) .

Untuk mengetahui soal tes kelas kontrol dan kelas eksperimen berdistribusi normal maka dilakukan uji normalitas dengan menggunkan perangkat SPSS dengan taraf signifikansi $(\alpha) 5$ $\%$ dimana jika diperoleh taraf signifikansi > 0.05 maka data berdistribusi normal, sebaliknya jika diperoleh taraf signifikansi $<0.05$ maka data tidak berdistribusi normal.

Tabel 2. Uji Normalitas Data Kontrol Dan Eksperimen

\begin{tabular}{llll}
\hline \multicolumn{4}{c}{ Tests of Normality } \\
\hline jenis Test & \multicolumn{3}{l}{ Kolmogorov-Smirnov } \\
\cline { 2 - 4 } & Statistic & Df & Sig. \\
\hline Nilai siswa & & & \\
Kontrol & .144 & 26 & .173 \\
Eksperimen & .133 & 31 & .174 \\
& & & \\
\hline
\end{tabular}

${ }^{\mathrm{a}}$ Lilliefors Significance Correction

Tabel 2 di atas menunjukan hasil uji normalitas soal kontrol dan eksperimen, dimana data tersebut diperoleh signifikansi soal kontrol sebesar 0.173 dan soal eksperimen sebesar 0.174 . Karena signifikansi soal kontrol dan eksperimen >0.05, dapat disimpulkan bahwa data hasil tes (kontrol dan eksperimen) berdistribusi normal.

\section{SIMPULAN}

Rata-rata hasil belajar siswa kelas vii smp negeri 1 tebas pada mata pelajaran ips terpadu dalam materi keragaman flora dan fauna di Indonesia pada kelas kontrol 69,62 sebesar dan pada kelas eksperimen sebesar 73,23. Berdasarkan hasil uji t dengan taraf signifikan 0,05 dan derajat kebebasan 55 dari tabel distribusi diperoleh $\mathrm{t}$ tabel 2,000. Ternyata $\mathrm{t}$ hitung lebih besar dari t tabel $(2.27>2.000)$, yang menyatakan bahwa terdapat perbedaan 
antara hasil belajar siswa kelas kontrol dengan kelas eksperimen sehingga dapat disimpulkan bahwa terdapat perbedaan hasil belajar siswa kelas kontrol dengan kelas eksperimen yang menerapkan metode inquiry.

\section{DAFTAR PUSTAKA}

Ahmad, Munib. 2004. Pengantar Ilmu Pendiikan. Semarang : UPT UNNES Press.

Hadi, A dan Haryono. 2005. Metodologi Penelitian Pendidikan. Bandung : Pustaka Setia.

Hamdani. (2011). Strategi Belajar Mengajar. Bandung: Pustaka Setia.

Rusman. (2012). Model-Model Pembelajaran, Mengembangkan Profesionalisme Guru. Jakarta: PT Raja Grafindo.

Sanjaya, Wina. (2010). Strategi Pembelajaran Berorientasi Standar Proses Pendidikan. Bandung : Prenada Media Group.

Subana. Rahadi, M. \& Sudrajat. (2012). Statistik Pendidikan. Bandung: Pustaka Setia.

Sugiyono. 2012. Metode Penelitian Pendidikan Pendekatan Kuantitatif, Kualitatif, dan $R n D$. Bandung: Alfabeta. 